\title{
Analysis of the $L A M B 3$ gene in a junctional epidermolysis bullosa patient reveals exonic splicing and allele-specific nonsense-mediated mRNA decay
}

Birgit Buchroithner ${ }^{1}$, Alfred Klausegger ${ }^{1}$, Ulrike Ebschner ${ }^{2}$, Ingrun Anton-Lamprecht ${ }^{2}$, Gabriele Pohla-Gubo ${ }^{1}$, Christoph M Lanschuetzer ${ }^{1}$, Martin Laimer ${ }^{1}$, Helmut Hintner ${ }^{1}$ and Johann W Bauer ${ }^{1}$

${ }^{1}$ Department of Dermatology, Paracelsus Private Medical University of Salzburg, Salzburg, Austria and

${ }^{2}$ Institute for Ultrastructure Research of the Skin, University of Heidelberg, Heidelberg, Germany

\begin{abstract}
How splicing, the process of intron removal in pre-messenger RNA (mRNA), is carried out with such fidelity in human cells is still not understood, although some general rules are being proposed mainly by in vitro experiments. These rules are currently being redefined by analysis of splicing mechanisms in patients presenting splicing defects. We analysed material of a patient suffering from junctional epidermolysis bullosa, a heritable blistering skin disease. Absence of laminin-5 protein together with hypoplastic hemidesmosomes at the dermo-epidermal junction in the patient's skin was shown by immunohistochemical analysis and immunoelectron microscopy. Subsequent DNA analysis revealed heterozygosity for the mutations R635X and $3009 \mathrm{C} \rightarrow \mathrm{T}$ in the $L A M B 3$ gene. The latter did not alter codon translation, but introduced an exonic splice site in exon 20. Interestingly, this exonic splice site, which presented a splice score of only 68.6, was preferentially used by the spliceosome over the wild-type splice site at the exon 20-intron 20 border, which showed a splice score of 92.2. LAMB3 mRNA was still detectable in RT-PCR analysis although the aberrantly spliced mRNA leads to a stop codon in exon $21,5^{\prime}$ of the commonly assumed $3^{\prime}$ border for nonsense-mediated mRNA decay. These results describe an exception to the proposed rules of pre-mRNA splicing and RNA degradation. Laboratory Investigation (2004) 84, 1279-1288, advance online publication, 16 August 2004; doi:10.1038/labinvest.3700164
\end{abstract}

Keywords: epidermolysis bullosa; laminin-5; nonsense-mediated mRNA decay; skin disease; splicing

Splicing of pre-messenger RNA (mRNA) describes the mechanism of intron removal and exon ligation leading to formation of mature mRNA. This process critically depends on accurate recognition of correct splice sites by spliceosomes. The position of a splice site is indicated by a highly conserved sequence at the exon-intron border, which usually is a sequence of eight nucleotides for the $5^{\prime}$ splice-site and a sequence of four nucleotides, preceded by a pyrimidine-rich region for the $3^{\prime}$ splice site. Nevertheless, a splice site sequence of neighbouring nucleotides can deviate more or less from the consensus, resulting in a 'weaker' or a 'stronger' splice site. The latter is more tightly bound by

Correspondence: Professor Dr JW Bauer, MD, PhD, Department of Dermatology, Paracelsus Private Medical University of Salzburg, Muellner Hauptstrasse 48, A-5020 Salzburg, Austria.

E-mail: jo.bauer@salk.at

Received 27 April 2004; revised and accepted 11 July 2004; published online 16 August 2004 splicing factors and therefore used preferentially. ${ }^{1,2}$ The strength of a splice site can be described by a splice site score with an optimum of 100 for a very strong splice site. ${ }^{3}$ Recently, splice site selection has been shown to be modulated by serine/arginine-rich proteins and heterogeneous nuclear riboproteins, which in turn activate/repress U1 small nuclear ribonucleoproteins responsible for selection of $5^{\prime}$ splice sites. ${ }^{4}$ Mutations changing the consensus sequence can inactivate a splice site. As a result, sequences similar to consensus sequences in exons or introns are targeted by the spliceosome instead. This process called 'cryptic splicing' often leads to the loss of coding sequences, inclusion of noncoding sequences, frameshifts and premature termination codons (PTC), what either results in truncated protein products or activates nonsense-mediated mRNA decay (NMD). NMD is a mRNA surveillance mechanism that ensures mRNA quality by targeting mRNAs that harbour PTC for rapid degradation. PTC in higher eukaryotes only provoke NMD when 
they occur $5^{\prime}$ of 55 nucleotides upstream of the last exon-exon junction on spliced RNA. ${ }^{5-7}$ More often than not cryptic splicing is provoked by mutations that alter a given splice site thus impairing or deleting the splice signal. Rarely, mutations generate new splice sites when the original splice site is still intact and, moreover, sends a strong splice signal. ${ }^{8-10}$

Junctional epidermolysis bullosa (JEB) is characterized by blistering in skin and mucous membranes caused by separation within the lamina rara (also called the lamina lucida) of the dermo-epidermal junction. It can be caused by reduction or total lack of laminin-5, an important protein of the dermoepidermal basement membrane zone. Laminin-5, an isoform of the classical laminin-1, is a heterotrimer consisting of the polypeptide chains $\alpha 3, \beta 3$ and $\gamma 2$, which are encoded by the genes LAMA3, LAMB3 and $L A M C 2$, respectively. Mutations leading to truncation or total lack of one of these chains prevent laminin-5 assembly, what results in skin detachment. ${ }^{11,12}$ The complete loss of laminin-5 protein causes a very severe phenotype of blistering skin disease usually leading to the early demise of the patient within the first 2 years of life (HerlitzJEB). Examination of the EB mutation database shows that the combination of PTC on both alleles of the $L A M B 3$ gene usually causes this Herlitz-JEB variant by complete NMD of $L A M B 3$ mRNA. ${ }^{13}$ Only few cases of nonlethal JEB caused by laminin-5 mutations have been reported to date. These nonHerlitz JEB (nH-JEB) phenotypes usually are caused by nonsense mutation in combination with missense mutations in the $L A M B 3$ gene preserving some residual $\beta 3$ polypeptide, which is then available for laminin-5 protein assembly.

We report on a patient suffering from nH-JEB caused by a nonsense mutation in combination with a mutation that creates an exonic splice site. RNA analysis revealed preferential usage of this exonic splice site, which was not predicted by the standard rules of splicing. Furthermore, low levels of functional $L A M B 3$ mRNA escaping NMD could be shown although PTC are present on both alleles.

\section{Patient, materials and methods}

\section{Clinical Features}

The patient, a female born in 1964, suffers since birth from generalized skin blistering and erosions that heal with atrophic scars (Figure 1b-d). Later, nail dystrophy predominantly affecting the toe nails (d) and tooth decay (a) have been evolving. The hair of the scalp is normal; however, alopecia is found on eyebrows, axillary and pubic hair. Mild involvement of the oral mucosa is present. The patient gave birth to two healthy daughters. The parents of the index patient had not been available for analysis.

\section{Transmission Electron Microscopy (TEM)}

A biopsy sample from lesional skin of the back was prepared separately for intact and blistered skin areas for TEM ( $3 \%$ glutardialdehyde and $1 \%$ osmic acid, both in cacodylate buffer at $\mathrm{pH}$ 7.4; . epoxy resin Epon 812 syn. glycidether 100). Ultrathin sections were treated with uranyl acetate and lead citrate. Electron microscope: Philips EM 400 (80 kV acceleration voltage).

\section{Immunohistochemistry}

Frozen unfixed sections of normal appearing patient skin were used. A biotin-streptavidin-peroxidasecomplex method was applied using various primary polyclonal and monoclonal antibodies directed against epitopes of laminin-5, uncein, and collagen type VII (see below).

\section{Antigen Mapping}

Antigen mapping was performed according to Hintner et al. ${ }^{14}$ Cryostat sections $(6 \mu \mathrm{m})$ from cryopreserved normal appearing patient skin and normal human skin (control) were mounted on glass slides. First step antibodies against various proteins in the dermo-epidermal junction, including laminin-5 monoclonal antibody (mAb) (GB3, Sera-Lab, Belton, England, dilution 1:50) were incubated for $30 \mathrm{~min}$. The sections were washed three times for $10 \mathrm{~min}$ in PBS followed by the incubation with the second step conjugated FITC antibody, which was goat anti-mouse IgG (Chemicon International, Temecula, CA, USA, dilution 1:100) for laminin-5. Again the slides were washed, mounted and examined with an Axioskop immunofluorescence microscope (Zeiss, Vienna, Austria).

\section{Immunoelectron Microscopy (IEM) by Postembedding Methods}

Mild prefixation of tissue samples was performed at room temperature $(0.1 \%$ glutardialdehyde $+0.2 \%$ picric acid), followed by embedding in Unicryl resin at $-20^{\circ} \mathrm{C}$ and curing at $-15^{\circ} \mathrm{C}$. Ultrathin sections, mounted on nickel grids, were incubated with primary antibodies recognizing laminin-5 (antikalinin polyclonal antibody (pAb) 4101) and collagen type VII (pAb 1854, mAb NP185) and with secondary antibodies labelled with $10 \mathrm{~nm}$ immunogold and finally treated with uranyl acetate and lead citrate. A Philips EM $400(80 \mathrm{kV})$ at primary magnifications of 19500 and 33000 was used for IEM analysis.

\section{Polymerase Chain Reaction (PCR)}

Genomic DNA was isolated from peripheral blood of the patient as recommended by the manufacturer's protocol (Puregene $^{\mathrm{TM}}$ DNA Isolation Kit, Gentra, 

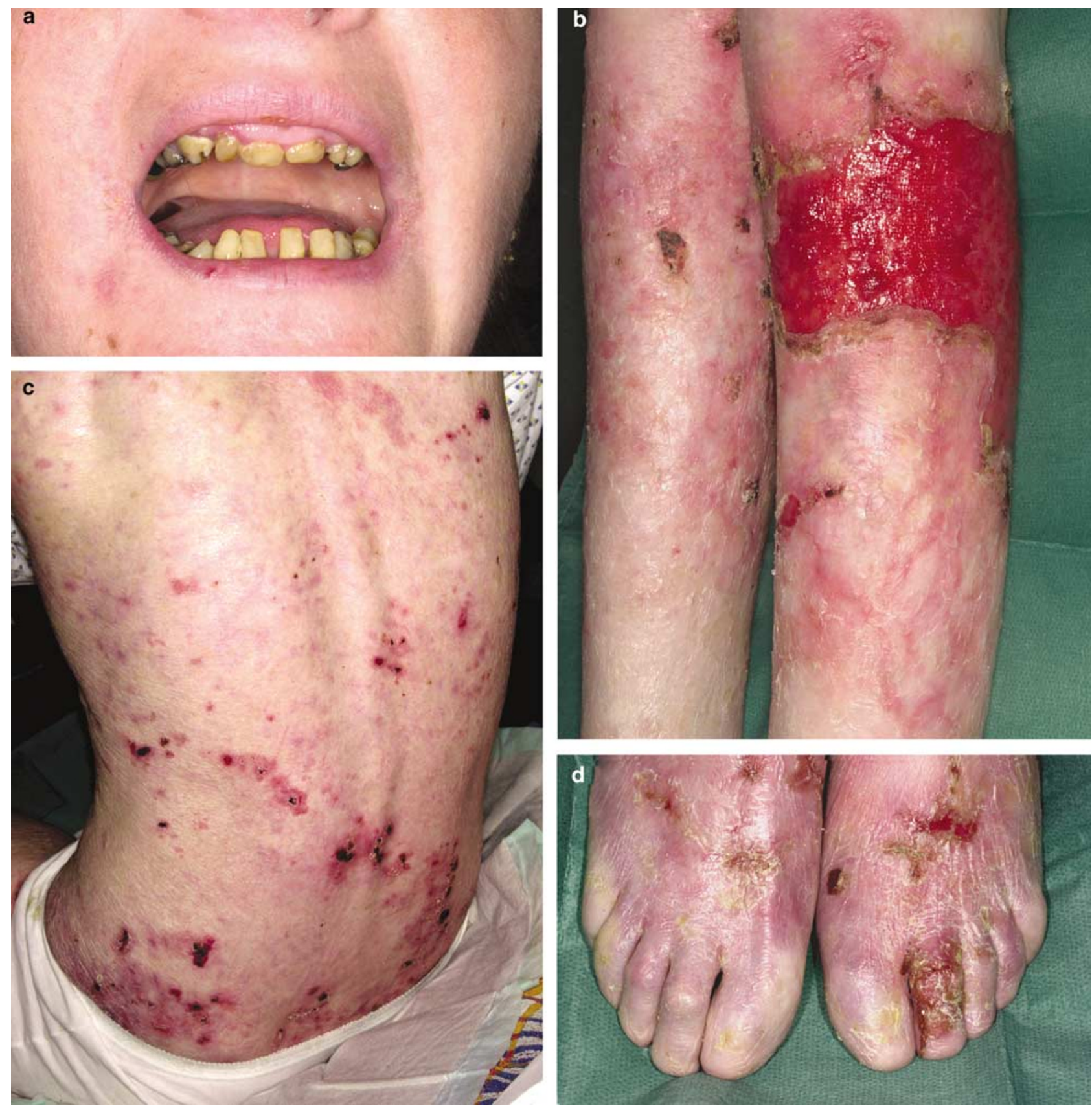

Figure 1 Clinical presentation of the index patient at the age of 39 years: (a) enamel hypoplasia and severe caries; (b) chronic erosions and atrophic scarring on the lower legs; (c) periodically recurring erosions and blistering on the back of the patient; (d) complete toe nail dystrophy.

Minneapolis, MN, USA). Primers for amplification of exons $2-23$ of the $L A M B 3$ gene were acquired from MWG-Biotech (Ebersberg, Germany) according to the sequences published by Pulkkinen et $a l^{15}$ except for some primers, which were redesigned for improved specificity. For amplification, $100 \mathrm{ng}$ of genomic DNA was used as template in a volume of $30 \mu \mathrm{l}$ containing $1 \times$ enzyme buffer, $1.5 \mathrm{mM} \mathrm{MgCl}_{2}$, $6 \%$ DMSO, $0.2 \mathrm{mM}$ dNTPs, $10 \mathrm{pmol}$ of each primer and $1.25 \mathrm{U}$ polymerase (BioThermRed ${ }^{\mathrm{TM}}$, GeneCraft, Muenster, Germany). Amplification conditions were: initial denaturation at $94^{\circ} \mathrm{C}$ for $5 \mathrm{~min}, 40$ cycles of denaturation $\left(94^{\circ} \mathrm{C}\right.$ for $\left.15 \mathrm{~s}\right)$, annealing $\left(57^{\circ} \mathrm{C}\right.$ or $55^{\circ} \mathrm{C}$ for $\left.30 \mathrm{~s}\right)$ and extension $\left(72^{\circ} \mathrm{C}\right.$ for $\left.30 \mathrm{~s}\right)$, followed by a final extension step at $72^{\circ} \mathrm{C}$ for $5 \mathrm{~min}$. PCR products were analysed by agarose gel electrophoresis ( $1 \%$ agarose) along with $250 \mathrm{ng}$ of a molecular weight marker (100 bp DNA Ladder, New England Biolabs, Beverly, MA, USA).

\section{Conformation-Sensitive Gel Electrophoresis}

Mutation detection was performed by heteroduplex scanning using conformation-sensitive gel electro- 
phoresis (CSGE). ${ }^{16}$ PCR-products were denaturated at $98^{\circ} \mathrm{C}$ for $5 \mathrm{~min}$ and cooled down to $68^{\circ} \mathrm{C}$ for $60 \mathrm{~min}$ to allow heteroduplex formation. Loading buffer was added and samples were loaded on a $10 \%$ polyacrylamide gel and run at $700 \mathrm{~V}$ overnight. Heteroduplices were visualized by gel staining with ethidium bromide solution $(1 \mu \mathrm{g} / \mathrm{ml})$.

\section{Sequencing}

PCR products displaying heteroduplices or showing newly introduced restriction sites were sequenced at MWG-Biotech with a concentration of $20 \mathrm{ng}$ DNA/ 100 bases and 10 pmol of the respective primers.

\section{RNA Isolation}

Total RNA was extracted from the patient's skin biopsy from normal appearing skin using a RNA extraction kit (RNeasy ${ }^{\mathbb{R}}$ Mini Kit, Qiagen, Hilden, Germany) according to the manufacturer's recommendations. RNA was visualized by formaldehyde agarose gel electrophoresis ( $1.2 \%$ agarose).

\section{Complementary DNA (cDNA)}

cDNA (first strand) was synthesized by M-MLV Reverse Transcriptase (Promega, Madison, WI, USA) with oligo(dT) primers corresponding to the manufacturer's instructions using $1 \mu \mathrm{g}$ total RNA isolated from the patient's skin biopsy.

\section{Restriction Enzyme Fragment Length Polymorphism}

R635X: The nonsense mutation R635X creates a new restriction site for the restriction endonuclease BgIII in exon 14. Therefore, exon 14 was amplified by PCR using primers according to Pulkkinen et $a 1^{15}$ and a BgIII digest was performed according to the manufacturer's recommendations (New England Biolabs). The enzyme cleaves the $578 \mathrm{bp}$ PCR product harbouring the mutation into two smaller bands of 428 and $150 \mathrm{bp}$ length.

$3009 C \rightarrow T:$ A KpnI digest was performed to investigate splice site usage. Primers for amplification were $5^{\prime}$-ctc aca gat tca atc cag tgc- $3^{\prime}$ (sense) and $5^{\prime}$-att ctc tca aat ccc tct tgg- $3^{\prime}$ (antisense) binding to exon 18 and exon 22 on LAMB3 mRNA (cDNA), respectively.

Amplification conditions were: $94^{\circ} \mathrm{C}$ for $5 \mathrm{~min}, 40$ cycles of denaturation $\left(94^{\circ} \mathrm{C}\right.$ for $\left.30 \mathrm{~s}\right)$, annealing $\left(56^{\circ} \mathrm{C}\right.$ for $\left.30 \mathrm{~s}\right)$ and extension $\left(72^{\circ} \mathrm{C}\right.$ for $\left.45 \mathrm{~s}\right)$ followed by a final extension step at $72^{\circ} \mathrm{C}$ for $5 \mathrm{~min}$. Nested PCR was performed for improved product yield at same amplification conditions as described above.

Nested primers were: $5^{\prime}$-ttc cta aca gac ccc gac ac$3^{\prime}$ (sense) hybridizing to exon 18 and $5^{\prime}$-ggc act caa tgc ctg ctc g-3' (antisense) hybridizing to exon 21. The resulting product was $531 \mathrm{bp}$ in size. The KpnI digest was performed according to the manufacturer's protocol (New England Biolabs) causing cleavage only in case of correct splice site usage on the allele harbouring the mutation $3009 \mathrm{C} \rightarrow \mathrm{T}$.

\section{Quantification of LAMB3 mRNA}

Amplification conditions of $L A M B 3$ cDNA (first strand) were: $94^{\circ} \mathrm{C}$ for $5 \mathrm{~min}, 40$ cycles of denaturation $\left(94^{\circ} \mathrm{C}\right.$ for $\left.15 \mathrm{~s}\right)$, annealing $\left(56^{\circ} \mathrm{C}\right.$ for $\left.30 \mathrm{~s}\right)$ and extension $\left(72^{\circ} \mathrm{C}\right.$ for $\left.30 \mathrm{~s}\right)$ followed by a final extension step at $72^{\circ} \mathrm{C}$ for $5 \mathrm{~min}$. Primers for amplification of $L A M B 3$ cDNA were: $5^{\prime}$-ttc cta aca gac ccc gac ac- $3^{\prime}$ (sense) hybridizing to exon 18 and $5^{\prime}$-att ctc tca aat ccc tct tgg- $3^{\prime}$ (antisense) binding to exon 22. The resulting PCR product was $551 \mathrm{bp}$ in size. Amplification of the housekeeping gene glyceraldehyde-3phosphate dehydrogenase $(G A P D H)$ served as internal reference for equivalent loading. $G A P D H$ primers were $5^{\prime}$-aat CCC atc acc atc ttc ca- $3^{\prime}$ (sense) and $5^{\prime}$-cct gct tca cca cct tct tg- $3^{\prime}$ (antisense) for a 580 bp PCR product.

\section{RT-PCR Analysis}

Primers for amplification of $L A M B 3$ cDNA were: $5^{\prime}$ ttc cta aca gac cCc gac ac- $3^{\prime}$ (sense) and $5^{\prime}$-agg tgg cat agt aga gca cg- $3^{\prime}$ (antisense) binding to exon 18 and exon 23 on LAMB3 mRNA (cDNA), respectively. Amplification conditions were: $94^{\circ} \mathrm{C}$ for $5 \mathrm{~min}, 40$ cycles of denaturation $\left(94^{\circ} \mathrm{C}\right.$ for $\left.30 \mathrm{~s}\right)$, annealing $\left(57^{\circ} \mathrm{C}\right.$ for $\left.30 \mathrm{~s}\right)$ and extension $\left(72^{\circ} \mathrm{C}\right.$ for $\left.1 \mathrm{~min}\right)$ followed by a final extension step at $72^{\circ} \mathrm{C}$ for $5 \mathrm{~min}$. The resulting PCR product was $820 \mathrm{bp}$ in size.

\section{Splice Score Calculation}

In 1987, Shapiro and Senapathy ${ }^{3}$ examined 542 primate splice junction sequences using the GENBANK database and found that a sequence of eight nucleotides (position -2 to +6 ) is highly conserved at the boundary between an exon and an intron, the $5^{\prime}$ splice site. They tabulated nucleotide frequencies and based on this nucleotide weight table they developed a scoring and ranking scheme to find the most probable $5^{\prime}$ splice site in a given sequence: 'score $=100$ ( $t$-mint $) /($ maxt-mint $)$ ' where mint and maxt are the minimum and maximum possible totals, that is, the sum of the lowest and highest percentages in each of the eight positions, and $t$ is the total of percentages for the given sequence being scored. By using this formula, any subsequence composed of eight nucleotides can be scored with regard to its potential as a splice site, obtaining a score between 0 and 100 . The higher the score, the more probable it is that the examined sequence is a $5^{\prime}$ splice site.

We applied this formula to rank two $L A M B 3$ sequences according to their splice site potential: 
AGgtgagg, the natural $5^{\prime}$ splice site (position -2 to +6 ) at the exon 20/intron 20 border and AGGTACCA, a sequence in exon 20 (nt3006-3013) that was altered by the mutation $3009 \mathrm{C} \rightarrow \mathrm{T}$. The sequences used for analysis were taken from the GENBANK Database Accession Number U17758.

\section{Results}

\section{Pedigree and Immunohistochemistry}

Mutation analysis was performed with DNA of the index patient, her husband as well as their oldest daughter (Figure 2). Immunohistochemical reaction patterns were virtually negative for laminin-5 in the patient's skin and normal in control skin, pointing to laminin-5 as the mutant protein target in our JEB case; labelling for collagen type VII was normal for both control and patient skin (data not shown). This observation was further confirmed in the antigen mapping investigation that showed severely reduced laminin-5 expression using mAb GB3 (Figure 3). Labelling for collagen type VII was normal for both control and patient skin (data not shown).

\section{Electron Microscopy}

TEM analysis of the patient's lesional skin (Figure $4 a-d)$ revealed junctional blister formation with separation in the space of the lamina rara, the blister roof formed by basal cells (BC) with remnants of hypoplastic hemidesmosomes at their undersurface (Figure 4c), and the basal lamina with attached anchoring fibrils (AF) (type VII collagen) covering the blister floor (Figure 4d). Intact dermo-epidermal junctions show varying amounts of hypoplastic hemidesmosomes and frequent basal lamina duplications. Hemidesmosomes mostly have poor attachment plates and immature or lacking sub-basal

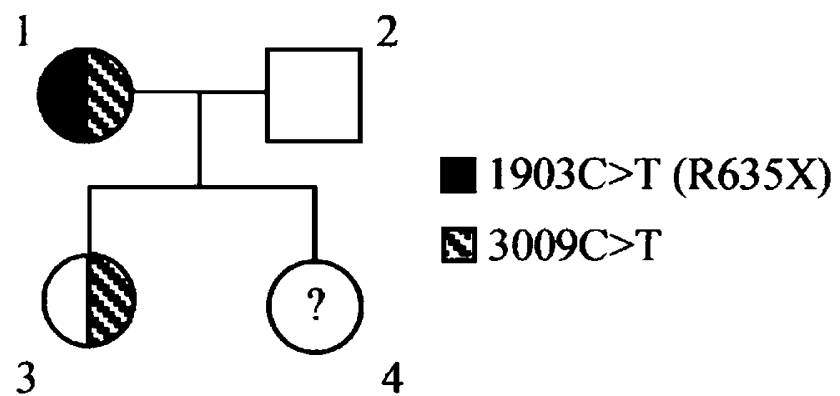

Figure 2 Pedigree of the nuclear family. The index patient (1), her husband (2) and their first daughter (3) were analysed. The patient is compound heterozygous for the mutations R635X and $3009 \mathrm{C} \rightarrow \mathrm{T}$ in the gene LAMB3. Her husband is genetically unaffected. The clinically unaffected daughter carries the allele harbouring the mutation $3009 \mathrm{C} \rightarrow \mathrm{T}$ as well as a wild-type allele stemming from her father. The patient gave birth to another healthy daughter. ${ }^{4}$ Here, mutation analysis has not been performed yet. dense plates, but anchoring filaments are visible in the lamina rara, and AF are prominent. Basal lamina detachment indicates repeated subclinical junctional separation and subsequent repair (Figure $4 a, b)$.

IEM analysis of JEB and control skin (Figure 4e, f) (Unicryl postembedding and immunogold labelling). The patient's skin samples showed almost no reaction with anti-kalinin pAb 4101 (recognizing laminin-5), except some very few, isolated gold granules in the lowermost lamina rara (not shown), although hypoplastic hemidesmosomes are excellently preserved (Figure 4e); labelling of AF for collagen type VII was normal with both primary antibodies applied (data not shown). Control skin samples readily reacted with the primary laminin-5
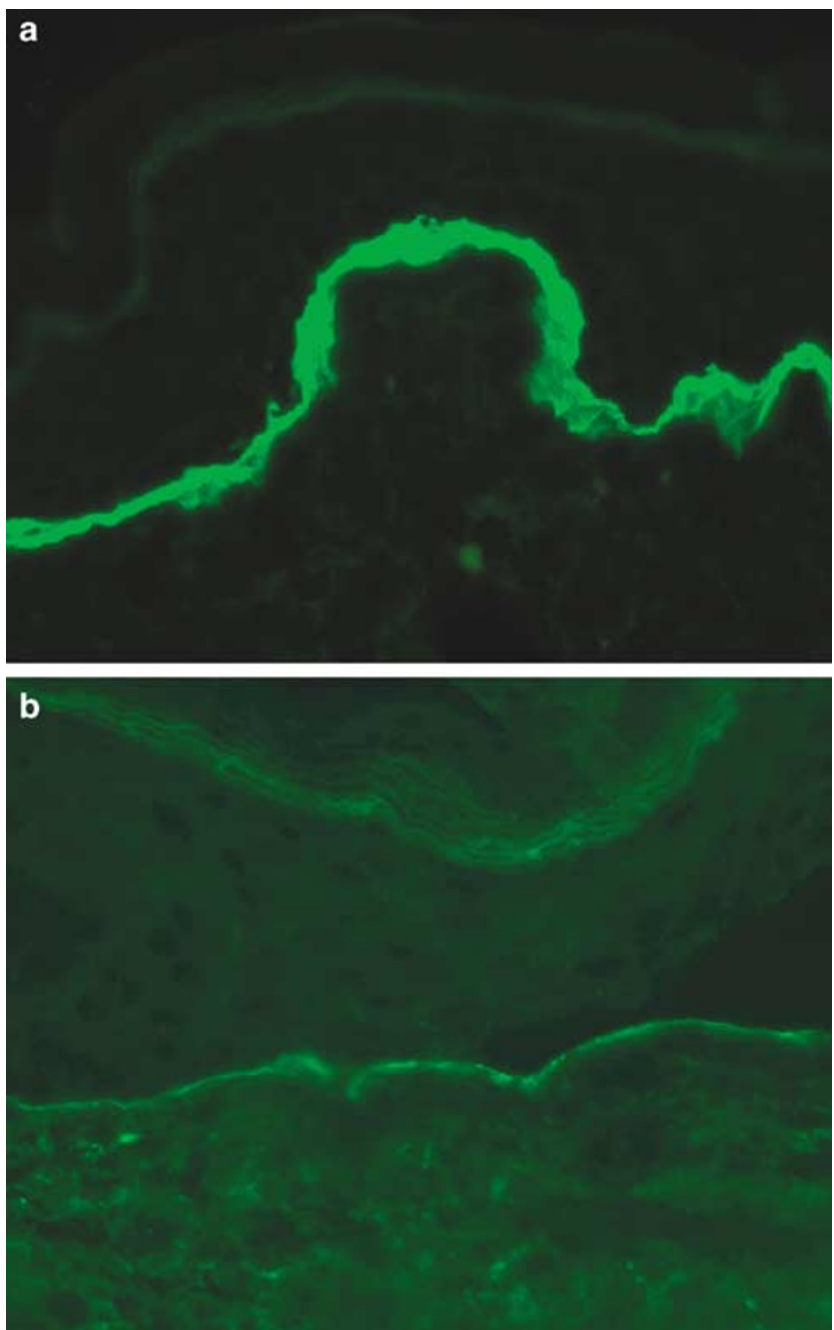

Figure 3 Antigen-mapping shows severe reduction of laminin-5 protein. (a) Immunofluorescence reveals a bright fluorescent band of laminin-5 in normal skin using mAb GB3. At the top of the picture two lines of autofluorescence generated by the stratum corneum can be seen. Magnification $\times 200$. (b) In patient skin severe reduction of laminin-5, but some protein expression preserved at the dermo-epidermal junction was detected. Magnification $\times 400$. 

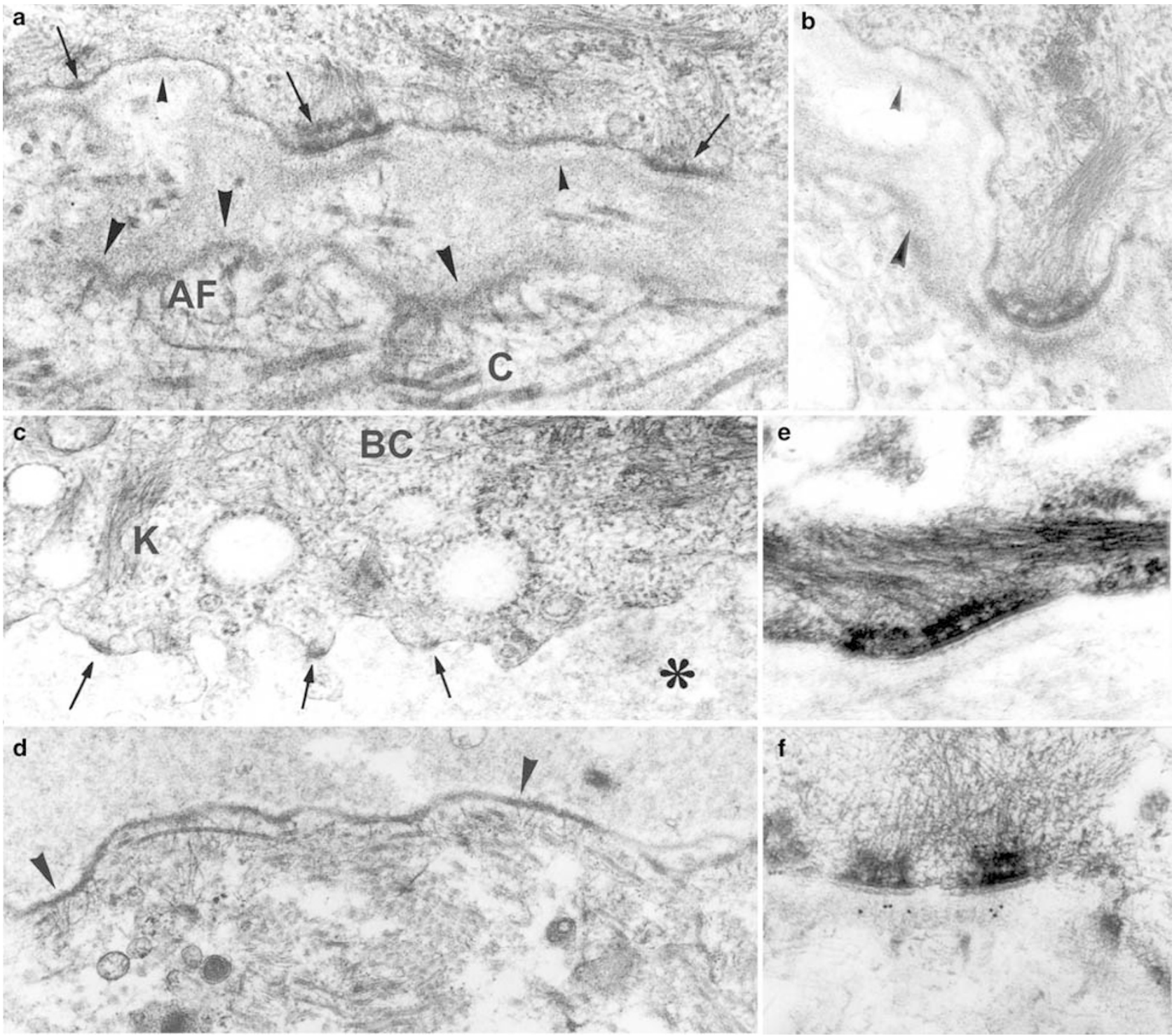

Figure 4 TEM and IEM of the patient's skin biopsy. (a and b) TEM. Intact dermo-epidermal junction with hypoplastic hemidesmosomes (arrows in (a)), the central one with a clear cytoplasmic attachment plate and inner plate with keratin filaments, fine anchoring filaments, but only an immature subbasal dense plate in the lamina rara. The best hemidesmosome found by TEM is shown in (b). Basal lamina detachment, very typical of JEB, indicates repeated subclinical junctional separation and subsequent repair: Old lamina densa fragments (large arrowheads) with attached AF (type VII collagen) are of higher density and thickness than the newly formed basal lamina along the plasma membrane (small upward arrowheads). C = Collagen fibrils. (c and d) TEM. The blister (*) is junctional. It has formed in the space of the lamina rara below the plasma membrane of BC with remainders of hypoplastic hemidesmosomes at the blister roof (arrows in (c)) and above the basal lamina or lamina densa covering the blister floor (arrowheads in (d)). K=Keratin filaments. (e and f) IEM of the patient's skin (e) and of control skin (f). Unicryl embedding and $10 \mathrm{~nm}$ immunogold-labelling of intact junction areas for laminin-5 with the polyclonal antikalinin antibody pAb 4101 (recognizing laminin-5). In the patient's skin sample (e), antibody binding is negative (except some very few, isolated gold granules in the lowermost lamina rara, not shown) and subbasal dense plates are hypoplastic, although cytoplasmic domains of hemidesmosomes are well developed. In the control skin sample (f), the gold-labelled antikalinin antibody, recognizing laminin-5, is located exclusively in the upper lamina densa at the lamina densa-lamina rara interface in the location of laminin-5, but not in the lamina rara in connection with anchoring filaments. Mature hemidesmosomes line the plasma membrane; their sub-basal dense plates, attachment plates and inner plates are well visible by IEM. Magnifications $\times 43000($ TEM, (a)-(c), $\times 20000($ TEM (d)), $\times 73000($ IEM, (e) and (f)).

antibody pAb 4101 (Figure 4f). However, gold granules are exclusively located in the upper lamina densa or at the lamina rara interface and not in association with AF. Many normal mature hemidesmosomes line the dermo-epidermal junction (Figure 4f).

\section{Identification of the Common Nonsense Mutation R635X in the LAMB3 Gene}

A BgIII restriction enzyme digest of the PCR product spanning exon 14 resulted in three fragments (578, 428 and $150 \mathrm{bp}$ ) for the patient's probe and showed only one band at $578 \mathrm{bp}$ for the control (Figure 5a). 
The fragment at $578 \mathrm{bp}$ corresponds to the wild-type allele, whereas the others result from the introduction of a BgIII restriction site on the second allele. Automated sequencing verified the heterozygous nonsense mutation R635X at position 1903 in the $L A M B 3$ gene of the index patient (Figure 5b).

\section{Identification of the Mutation $3009 \mathrm{C} \rightarrow \mathrm{T}$ in the $L A M B 3$ Gene and Analysis of Its Impacts on Splicing}

The patient's $L A M B 3$ genomic DNA was scanned by CSGE. Since no evidently pathogenic mutations could be found polymorphisms were further analysed. A $\mathrm{C} \rightarrow \mathrm{T}$ transition at nucleotide position 3009 in exon 20 had first seemed to be a translationally silent mutation as both triplets, GGC as well as GGT code for the amino-acid glycine (Figure 5c). For further investigation RT-PCR with patient's mRNA isolated from a skin biopsy was performed with primers flanking exon 20. Here, gel electrophoresis displayed two different transcription fragments: one at $820 \mathrm{bp}$ constituting the normal transcript of the $L A M B 3$ gene and a second missing $44 \mathrm{bp}$, indicating a splice defect on the second allele (Figure 5d). Subsequent sequencing of the proband's cDNA (Figure 5e) proved that the sequence AGGT introduced by the mutation $3009 \mathrm{C} \rightarrow \mathbf{T}$ acts as an exonic splice site competing with the original donor splice site at the exon/intron 20 border. Aberrant splicing results in the loss of $44 \mathrm{bp}$ of exon 20 . This causes a frameshift that consequently leads to a premature termination codon in exon 21, 406 nucleotides $5^{\prime}$ of the physiologic termination codon in exon 23 (Figure 6a). By using RESCUE-ESE (http://genes. mit.edu/burgelab/rescue-ese), an online tool to predict exonic splicing enhancers (ESE), it was excluded that this nucleotide change results in alteration of known ESEs (not shown). However, by using the RNA secondary structure prediction tool MFOLD (http://www.bioinfo.rpi.edu/applications/ $\mathrm{mfold} / \mathrm{old} / \mathrm{rna}$ /form1.cgi), it was concluded that a minor change in the RNA secondary structure neighbouring the mutation occurs (not shown).
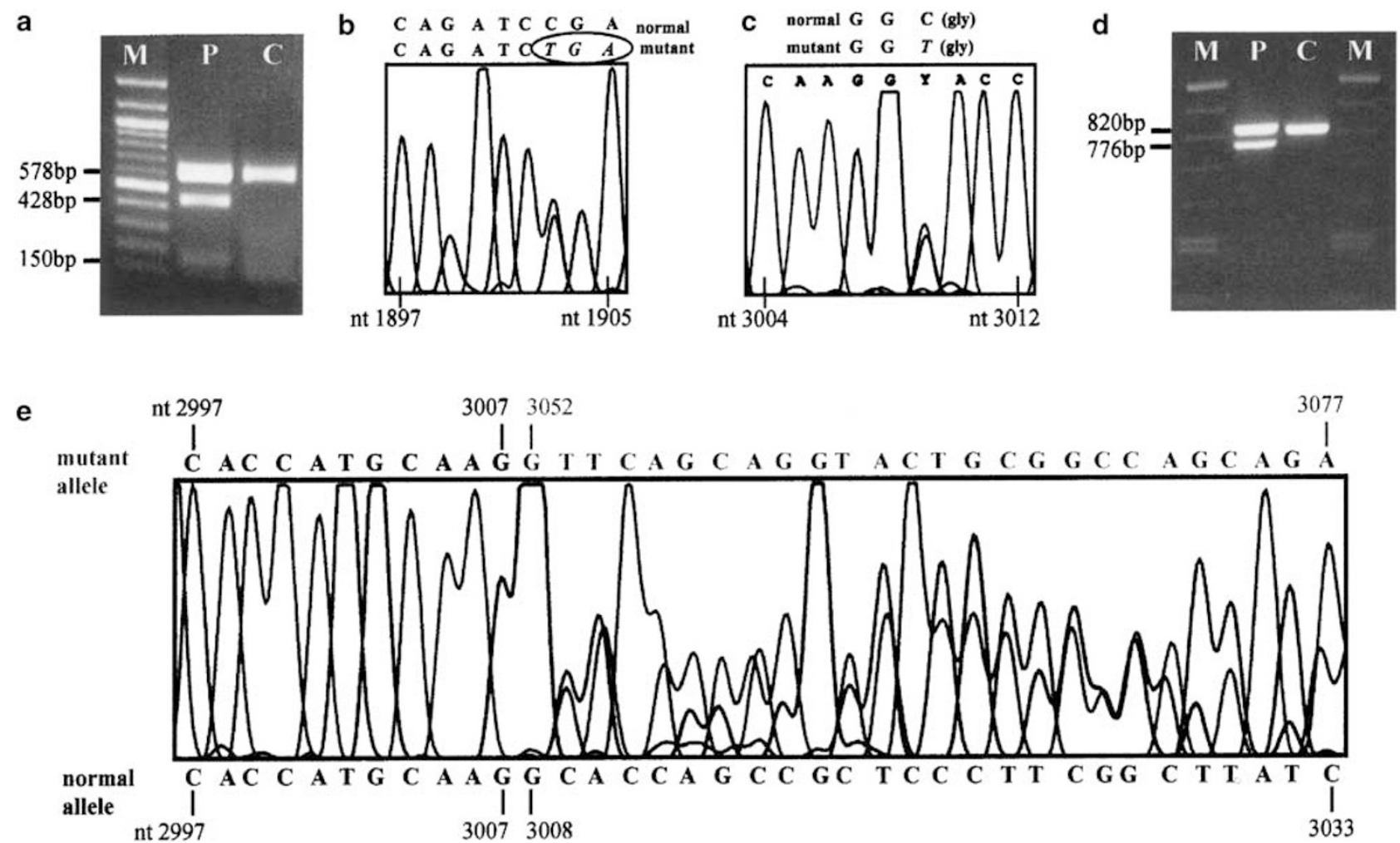

Figure 5 Verification of mutations on both alleles of the gene LAMB3. (a) Restriction enzyme digest with BgIII. The patient's PCR product of exon 14 showed three digest products, at 578,428 and $150 \mathrm{bp}(\mathrm{P})$. The $578 \mathrm{bp}$ band corresponds to the wild-type allele and is also seen with the control (C). The 428 and 150 bp fragments result from the introduction of a BglII restriction site by the mutation R635X. Molecular weight marker (M). (b) Automated sequencing. The sequence shows that the patient is heterozygous for a $\mathrm{C} \rightarrow \mathrm{T}$ transition at position 1903 (exon 14) in the gene LAMB3. The transition results in a premature termination codon (TGA) known as R635X. (c) Identification of the single basepair transition $3009 \mathrm{C} \rightarrow \mathrm{T}$ in exon 20 ( $L A M B 3$ ) by automated sequencing. The translation of codon 1003 is not altered by the mutation as both sequences code for the amino-acid glycine (gly). (d) RT-PCR analysis of LAMB3 mRNA (exons 18-23). Two different transcripts are present in our patient $(\mathrm{P})$ as displayed by agarose gel electrophoresis. The $820 \mathrm{bp}$ fragment is of normal size and is also seen with the control mRNA (C). The smaller fragment lacks 44 bp due to aberrant splicing. Lane P was overload for reasons of visibility. Molecular weight marker (M). (e) Automated sequencing of patient's LAMB3 cDNA. Two different transcripts are present. One is the wild-type sequence (normal allele) from nucleotide 2997 to 3033 of exon 20. The other transcript (mutant allele) stops at nucleotide 3007, lacks the following 44 nucleotides, continues with nucleotide 3052, the first base of exon 21. 


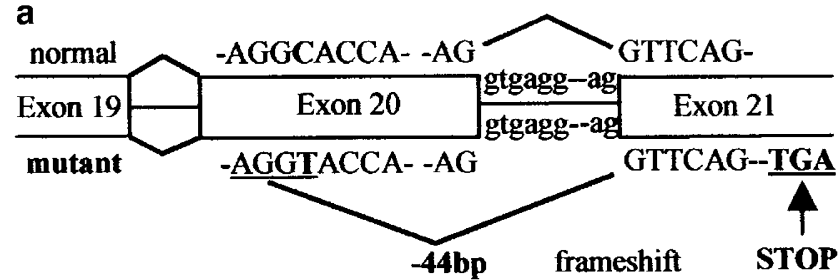

b
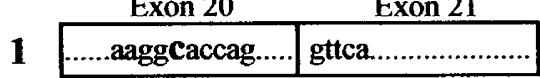

Exon 20

Exon 21

2

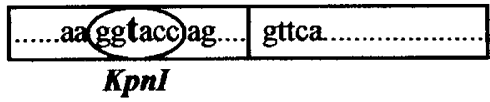

Exon $20 \quad$ Exon 21

3

\begin{tabular}{|l|l|l|}
\hline$\ldots . .$. aag & gttca..................... \\
\hline
\end{tabular}

Figure 6 (a) Schematic view of the splice defect and its consequences. The mutation $3009 \mathrm{C} \rightarrow \mathrm{T}$ transforms an exonic sequence into a new splice site competing with the original one at the exon 20/intron 20 border. Aberrant splicing causes the deletion of 44 nucleotides in exon 20. This leads to a frameshift and a premature termination codon (TGA) in exon 21. (b) Schematic view of the preservation or deletion of a KpnI restriction site due to splice site usage. (1) Wild-type allele: No KpnI restriction site exists in exon 20. (2) Mutated allele, correct splicing: The mutation $3009 \mathrm{C} \rightarrow \mathrm{T}$ introduces a restriction site for the enzyme KpnI in exon 20. (3) Mutated allele, aberrant splicing: Usage of the exonic splice site deletes the KpnI restriction site.

\section{Analysis of the Transcriptional Consequences of the Mutation $3009 \mathrm{C} \rightarrow \mathrm{T}$ in the $L A M B 3$ Gene}

Calculating the splice score according to Shapiro and Senapathy ${ }^{3}$ yielded a score of 92.2 for the wildtype donor splice site of exon 20/intron 20, which is fairly close to the optimum score of 100, suggesting it to be a strong splice site. The newly introduced splice site was calculated to have a score of only 68.6. To analyse to which extent this seemingly weak splice site is used by the spliceosome in comparison to the original splice site, we performed an allele-specific restriction enzyme digest. No restriction site for the enzyme KpnI is present in the wild-type allele (Figure 6b-1). The mutation $3009 \mathrm{C} \rightarrow \mathrm{T}$ introduces a restriction site for the endonuclease KpnI in exon 20 (Figure 6b-2), which is deleted in case of aberrant splice site selection (Figure 6b-3), but is preserved when the correct splice site is used. The KpnI digest of the PCR product spanning exon 18 to exon 21 (cDNA) showed only faintly visible digest fragments of 320 and $211 \mathrm{bp}$, although enzyme activity was shown to be sufficiently strong in the control reaction with the plasmid pcDNA3.1 harbouring one restriction site for the enzyme KpnI (Figure 7a). These results indicated that the exonic splice site is used preferentially and nearly exclusively, although the wild-type donor splice site is still intact and moreover is

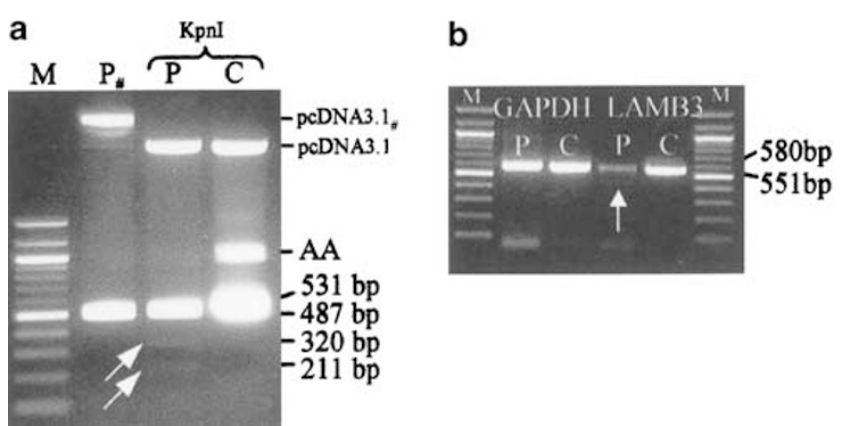

Figure 7 (a) KpnI digest of LAMB3 cDNA (exons 18-21) for investigation of splice site usage. Two faintly visible restriction fragments at 320 and $211 \mathrm{bp}$ (arrows) resulted from the KpnI digest in our patient's probe (P) but neither in the undigested patient's probe $\left(\mathrm{P}_{\#}\right)$ nor in the digested control $(\mathrm{C})$. The digest of the plasmid pcDNA3.1, which harbours one restriction site for the enzyme KpnI, showed proper enzyme activity in comparison to the undigested vector (pcDNA3.1 $1_{\# \text { ); }}$ molecular weight marker (M), amplification artifact (AA). Lane P was overload for reasons of visibility. Fragments at 531 and $487 \mathrm{bp}$ could not be separated properly $\left(\mathrm{P}_{\#}\right.$ and $\left.\mathrm{P}\right)$ by electrophoresis due to short runtime and low agarose concentration. (b) Quantification of LAMB3 mRNA steady-state levels in patient keratinocytes (LAMB3, P) vs unaffected control (LAMB3, C) shows significant reduction in the patient (arrow). The housekeeping gene GAPDH (P and C) served as internal standard. Molecular weight marker (M).

supposed to send a much stronger splice signal. Quantification by RT-PCR showed an almost complete loss of $L A M B 3 \mathrm{mRNA}$ in comparison to mRNA of the housekeeping gene GAPDH (Figure 7b).

\section{Discussion}

In this report we describe a translationally silent mutation in the LAMB3 gene creating an exonic splice site, which together with a nonsense mutation ultimately leads to nonlethal JEB. Most patients suffering from non-lethal JEB (mitis type, GABEB) carry mutations in the COL17A1 gene, the gene encoding BPAG2 (bullous pemphigoid antigen 2), a transmembrane protein of the dermo-epidermal junction. These cases mostly have lacking or very poor attachment plates and entirely miss anchoring filaments and sub-basal dense plates in the lamina rara, other than our patient with a milder hypoplasia of hemidesmosomes. This fact and the absence of laminin-5 immunoreaction in the dermo-epidermal junction zone indicated that our patient's JEB was caused by mutations in one of the three laminin-5 chain genes, LAMA3, LAMB3 or LAMC2. Laminin-5, which for years had been claimed to be the major protein of the anchoring filaments in the lamina rara, has now been shown by IEM to be located in the lamina densa and at the lamina rara interface and not in association with anchoring filaments. ${ }^{17,18}$ It seems to be the most critical part in the scaffolding linkage between $\mathrm{BC}$ and collagen matrices in the basement membrane zone. ${ }^{19}$ 
The transition $3009 \mathrm{C} \rightarrow \mathrm{T}$ in the $L A M B 3$ gene is a silent polymorphism, since GGC as well as GGT code for the amino-acid glycine. Only further investigations on RNA level revealed its pathogenic potential revealing the introduction of an exonic splice site in exon 20. Interestingly, this mutation creates a sequence that is recognized by the spliceosome instead of the wild-type donor splice site of exon 20, although the latter is still intact and is supposed to send a stronger splice signal to the spliceosome. The fact that a weak splice site caused by an exonic mutation is recognized by the spliceosome instead of the constitutive splice site might be explained by other components influencing that choice such as the length of an exon, the secondary structure of the region surrounding the splice site as well as the branchpoint sequence. ${ }^{20-22}$ In this regard, a minor alteration of the RNA secondary structure caused by $3009 \mathrm{C} \rightarrow \mathrm{T}$ was indicated by using the online tool MFOLD.

The commonly described $3^{\prime}$ border for NMD is located $50-55 \mathrm{bp} 5^{\prime}$ of the last exon/exon border. ${ }^{5-7}$ The degree of NMD is gene- and cell type-specific and can vary from two-fold up to 100 -fold. ${ }^{23}$ Allelespecific analysis of splice site usage by KpnI digest showed that the newly introduced splice site is preferentially used over the wild-type splice site farther downstream. This leads to the loss of $44 \mathrm{bp}$ and consequently to a PTC $62 \mathrm{bp}$ downstream in exon 21, 269 bp upstream of the last exon/exon border. Therefore, we concluded that residual amounts of $L A M B 3$ mRNA might originate from three sources: (1) Incomplete NMD from the R635X allele. However, the combination of two R635X mutations leads to complete loss of $L A M B 3 \mathrm{mRNA}$ as shown by Pulkkinen et al, ${ }^{12}$ thus excluding this possibility. (2) Correct splicing of the mutated $3009 \mathrm{C} \rightarrow \mathrm{T}$ allele. The KpnI digest produced only very faint bands of digest products proving that constitutive splicing is a minor cause of the residual $L A M B 3$ mRNA. (3) Incomplete NMD from the $3009 \mathrm{C} \rightarrow \mathrm{T}$ allele without constitutive splicing. In fact, analysis of a patient featuring a homozygous $3009 \mathrm{C} \rightarrow \mathrm{T}$ mutation showed higher amounts of heterotrimeric laminin-5 protein and milder symptoms in comparison to the heterozygous patient (A Klausegger, JW Bauer, unpublished observations). Therefore, it seems likely that the $-44 \mathrm{bp}$ version of the $3009 \mathrm{C} \rightarrow \mathrm{T}$ allele escapes NMD to a considerable degree and produces a relatively long, though incomplete laminin $\beta 3$ polypeptide, which together with minute amounts of correctly spliced mRNA serves as a template to constitute residual laminin-5 heterotrimers.

In summary, we show that sometimes, exact RNA analysis is necessary to decipher pathogenetic events in genetic diseases. The identification of the pathogenetic role of the exonic splice site paves the way for mutation-specific gene therapy using antisense oligonucleotides to block exonic splice site usage. ${ }^{24,25}$

\section{Acknowledgements}

We thank Dr R Hametner for providing excellent photographic material. This work was supported by grants from IEB-DEBRA Austria (BB and AK), the Department of Dermatology, Paracelsus Medical University of Salzburg (BB) and the Medizinische Forschungsgesellschaft (AK).

\section{References}

1 Nelson KK, Green MR. Splice site selection and ribonucleoprotein complex assembly during in vitro pre-mRNA splicing. Genes Dev 1988;2:319-329.

2 Ohshima Y, Gotoh Y. Signals for the selection of a splice site in pre-mRNA. Computer analysis of splice junction sequences and like sequences. J Mol Biol 1987;195:247-259.

3 Shapiro MB, Senapathy P. RNA splice junctions of different classes of eukaryotes: sequence statistics and functional implications in gene expression. Nucleic Acids Res 1987;15:7155-7174.

4 Caceres JF, Kornblihtt AR. Alternative splicing: multiple control mechanisms and involvement in human disease. Trends Genet 2002;18:186-193.

5 Cartegni L, Chew SL, Krainer AR. Listening to silence and understanding nonsense: exonic mutations that affect splicing. Nat Rev Genet 2002;3:285-298.

6 Hentze MW, Kulozik AE. A perfect message: RNA surveillance and nonsense-mediated decay. Cell 1999;96:307-310.

7 Maquat LE. Nonsense-mediated RNA decay in mammalian cells: a splicing-dependent means to downregulate the levels of mRNAs that prematurely terminate translation. In: Sonenberg N, Hershey JWB, Mathews MB (eds). Translational control of gene expression. Cold Spring Harbor Laboratory Press: Cold Spring Harbour, NY, 2000, pp 849-868.

8 Goldsmith ME, Humphries RK, Ley T, et al. 'Silent' nucleotide substition in a beta+-thalassemia globin gene activates splice site in coding sequence RNA. Proc Natl Acad Sci USA 1983;80:2318-2322.

9 Chen W, Kubota S, Teramoto T, et al. Silent nucleotide substitution in the sterol 27-hydroxylase gene (CYP 27) leads to alternative pre-mRNA splicing by activating a cryptic 5 splice site at the mutant codon in cerebrotendineous xanthomatosis patients. Biochemistry 1998;37:4420-4428.

10 Tavassoli K, Eigel A, Wilke K, et al. Molecular diagnostics of 15 hemophilia A patients: characterization of eight novel mutations in the factor VIII gene, two of which result in exon skipping. Hum Mutat 1998;12:301-303.

11 Matsui C, Wang CK, Nelson CF, et al. The assembly of laminin-5 subunits. J Biol Chem 1995;270: 23496-23503.

12 Pulkkinen L, Christiano AM, Gerecke D, et al. A homozygous nonsense mutation in the beta 3 chain gene of laminin 5 (LAMB3) in Herlitz junctional epidermolysis bullosa. Genomics 1994;24:357-360.

13 Nakano A, Chao SC, Pulkkinen L, et al. Laminin 5 mutations in junctional epidermolysis bullosa: molecular basis of Herlitz vs non-Herlitz phenotypes. Hum Genet 2002;110:41-51. 
14 Hintner H, Stingl G, Schuler G, et al. Immunofluorescence mapping of antigenic determinants within the dermal-epidermal junction in mechanobullous diseases. J Invest Dermatol 1981;76:113-118.

15 Pulkkinen L, McGrath JA, Christiano AM, et al. Detection of sequence variants in the gene encoding the $\beta 3$ chain of laminin 5 (LAMB3). Hum Mutat 1995;6:77-84.

16 Ganguly A, Rock MJ, Prockop DJ. Conformationsensitive gel electrophoresis for rapid detection of single-base differences in double-stranded PCR products and DNA fragments: evidence for solventinduced bends in DNA heteroduplices. Proc Natl Acad Sci USA 1993;90:10325-10329.

17 Ebschner U. Genetische Defekte an Kontaktstrukturen der dermo-epidermalen Junktionszone als Ursache atrophisierender und vernarbender Epidermolysen: Vergleichende ultrastrukturelle und immunelektronenmikroskopische Untersuchungen an Halbdesmosomen und Verankerungsfibrillen mit polyklonalen und monoklonalen Antikörpern. Thesis, University of Heidelberg, 1994.

18 Masunaga T, Shimizu H, Ishiko A, et al. Localization of laminin 5 in the epidermal basement membrane. J Histochem Cytochem 1996;44:1223-1230.
19 Anton-Lamprecht I, Gedde-Dahl Jr T. Epidermolysis bullosa. In: Rimoin DL, Connor JM, Pyeritz RE, Korf BR, Emery AE (eds). Emery and Rimoin's Principles and Practice of Medical Genetics, 4th edn. London: Churchill Livingstone, 2002, pp 3810-3897.

20 Brody E, Abelson J. The 'spliceosome': yeast premessenger RNA associates with a $40 \mathrm{~S}$ complex in a splicing-dependent reaction. Science 1985;228:963-967.

21 Furdon PJ, Kole R. Inhibition of splicing but not cleavage at the $5^{\prime}$ splice site by truncating human beta-globin pre-mRNA. Proc Natl Acad Sci USA 1986;83:927-931.

22 Solnick D. Alternative splicing caused by RNA secondary structure. Cell 1985;43:667-676.

23 Carter MS, Li S, Wilkinson MF. A splicing-dependent regulatory mechanism that detects translation signals. EMBO J 1996;15:5965-5975.

24 Bauer JW, Lanschuetzer C. Type XVII collagen gene mutations in junctional epidermolysis bullosa and prospects for gene therapy. Clin Exp Dermatol 2003;28:53-60.

25 Lacerra G, Sierakowska H, Carestia C, et al. Restoration of hemoglobin A synthesis in erythroid cells from peripheral blood of thalassemic patients. Proc Natl Acad Sci USA 2000;97:9591-9596. 